\title{
Breast Cancer: Evaluating Tumor Estrogen Receptor Status with Molecular Imaging to Increase Response to Therapy and Improve Patient Outcomes
}

\author{
Barbara J. Grabher, CNMT, RT(N) \\ Grabher Consulting and Specialty Services, Forest Hill, Maryland
}

CE credit: For CE credit, you can access the test for this article, as well as additional JNMT CE tests, online at https://www.snmmilearningcenter.org. Complete the test online no later than September 2023. Your online test will be scored immediately. You may make 3 attempts to pass the test and must answer $80 \%$ of the questions correctly to receive $1.0 \mathrm{CEH}$ (Continuing Education Hour) credit. SNMMI members will have their CEH credit added to their VOICE transcript automatically; nonmembers will be able to print out a CE certificate upon successfully completing the test. The online test is free to SNMMI members; nonmembers must pay $\$ 15.00$ by credit card when logging onto the website to take the test.

Current statistics show there are 3.5 million women in the United States living with breast cancer today, and approximately 330,000 new cases are diagnosed each year. Of these new cases, $81 \%$ are invasive cancers. About 41,000 women die from breast cancer each year. Thankfully, survival rates have increased over the years; however, an accurate diagnosis and treatment plan remain essential for patient survival and longevity. Sometimes breast cancer patients present their medical oncologist with a clinical dilemma on how their particular breast cancer should be treated, especially when standard options fail. Some breast cancer tumors respond to treatment, whereas others do not. Knowing the type of breast tumor a patient has, its estrogen receptor site status, and how it might respond to therapy are vital to effectively and successfully treating the patient, ultimately improving outcomes and overall survival rates. A potential new PET tracer, ${ }^{18} \mathrm{~F}$-fluoroestradiol (currently under Food and Drug Administration review for approval), may be a valuable tool for noninvasive evaluation of the estrogen receptor site status of a patients' primary tumor and secondary metastatic lesions. Imaging estrogen receptor sites is like obtaining a whole-body biopsy that can localize all estrogenpositive lesions in the body, enabling an effective treatment plan to be established for each patient. Estrogen-receptor-site imaging may be beneficial when a tumor is in an inaccessible location or is otherwise difficult to biopsy. Over the years, nuclear medicine has played a crucial role in providing medical oncologists with information helpful for accurately diagnosing and treating patients. With advances in both camera technology and radiopharmaceutical development, the information that nuclear medicine can provide has improved, allowing more accurate treatment and management of patients.

Key Words: breast cancer; estrogen receptor imaging; ${ }^{18} \mathrm{~F}-\mathrm{FES}$ (fluoroestradiol); molecular breast imaging; patient response to therapy; patient outcomes

J Nucl Med Technol 2020; 48:191-201

DOI: $10.2967 /$ jnmt.119.239020

Received Oct. 31, 2019; revision accepted Feb. 15, 2020.

For correspondence or reprints contact: Barbara J. Grabher, 801 Kensington Farm Ct., Forest Hill, MD 21050.

E-mail: barbara.grabher@gmail.com

Published online Feb. 28, 2020.

COPYRIGHT (C) 2020 by the Society of Nuclear Medicine and Molecular Imaging.
B reast cancer is the most common cancer in women, affecting 1 of every 8 women in their lifetime, and is second only to lung cancer as the leading cause of death in women (1). Although breast cancer is rare in men, it is possible, being diagnosed in approximately 1 of every 883 men (1). With breast cancer affecting 3.5 million women in the United States and approximately 330,000 new cases diagnosed and 41,000 deaths recorded each year $(2,3)$ an accurate diagnosis and treatment plan which includes imaging is essential for a patient to have the best outcome. Even though there are many different imaging modalities to help detect and diagnose the various types of breast tumors-benign, as well as malignant-each imaging modality has benefits and weaknesses.

Nuclear medicine breast imaging has become a diagnostic tool and adjunct to a patient's workup when standard breast cancer workups are inconclusive (4). This continuing education article reviews the role that nuclear medicine and molecular imaging have played over the years and explores a potential new ${ }^{18} \mathrm{~F}$ PET tracer that might aid medical oncologists in selecting the treatment that optimizes a patient's response and outcome. In particular, the article focuses on estrogen receptor (ER) site imaging with ${ }^{18}$ F-fluoroestradiol; furthers understanding of the types of breast cancer and how each responds to therapy; explains how knowing a breast cancer patient's tumor ER status (positive $[+]$ or negative $[-]$ ) is vital to deciding on the treatment (van Kruchten et al. (4) found that patients with ER + tumors are likely to respond to antihormonal therapy (4) whereas ER - tumors may not); and reviews 12 clinical trials of ${ }^{18} \mathrm{~F}$-fluoroestradiol, the basic ${ }^{18} \mathrm{~F}$ fluoroestradiol imaging protocol, the benefits of ER receptor imaging, and how ${ }^{18}$ F-fluoroestradiol PET compares with the gold standard (immunohistochemical staining of the primary tumor) for evaluating the ER status of a breast tumor. 


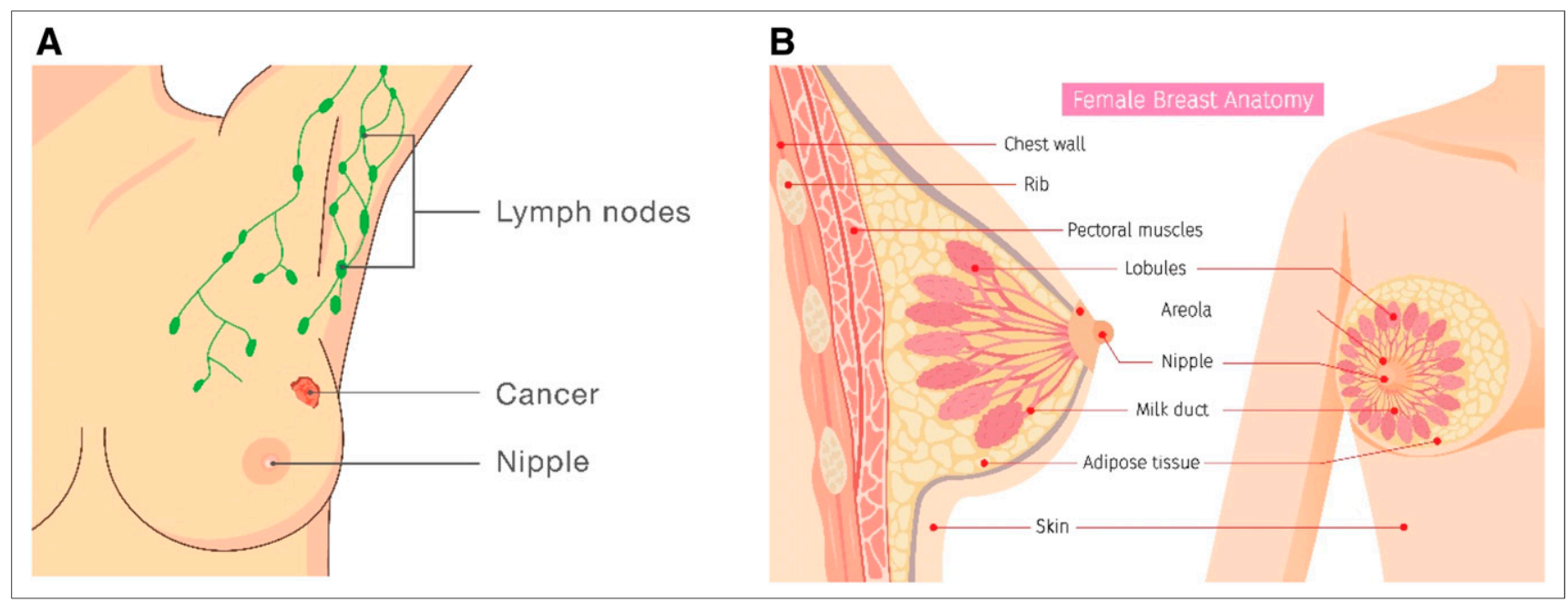

FIGURE 1. Illustrations of breast anatomy and lymphatic system. (A) Frontal view showing lymph nodes, cancer, and nipple. (B) Sagittal and frontal views showing additional anatomy. Critical structures when dealing with breast cancer are milk ducts, lobules, and nipple.

\section{BREAST CANCER FACTS AND STATISTICS}

Most breast cancers begin either in the lobules (glands used for milk production) or in the ducts that connect the lobules to the nipple. The rest of the breast is made up of fatty connective tissue and lymphatic tissue (5). Figure 1 illustrates the anatomy of the breast.

In the very early stages of breast cancer, there are usually no signs or symptoms; that is why screening is so crucial for early detection and successful treatment. The most common physical sign a patient might notice is a painless lump. Breast cancers may be localized to a single spot within the breast or may spread to lymph nodes in the armpit or to other parts of the body, such as the liver, lung, brain, and bones (6). Other, less common, symptoms are breast pain and heaviness; persistent changes in the breast such as swelling, thickness, or redness of the skin; and nipple abnormalities such as discharge, erosion, or retraction (5).

The American Cancer Society estimates that approximately one new case of breast cancer is diagnosed every 2 min (7). The average woman has a 12\% risk of developing breast cancer in her lifetime, which equates to a 1 in 8 chance of developing breast cancer (7). By race, the incidence per 100,000 women is 128.7 in non-Hispanic whites, 125.5 in non-Hispanic blacks, 100.7 in native Americans or native Alaskans, 91.9 in Hispanics or Latinas, and 90.7 in Asians or Pacific Islanders (5). Breast cancer in men is rare; it accounts for less than $1 \%$ of all cases in the United States. The incidence among men has increased slightly since 1975 , from 1.0 to 1.3 cases per 100,000 men (5).

\section{BREAST CANCER SURVIVAL RATES AND TRENDS}

Although over 3.5 million women are living with breast cancer, in recent years the incidence of breast cancer has increased slightly, by $0.04 \%$ per year (5). The incidence increases with age for both men and women (5); because people are living longer, this may be a reason the incidence is increasing slightly. Trends related to breast cancer deaths from 1989 to 2016 for women have dropped by almost $40 \%$ (7). Since 2007, breast cancer deaths have remained steady in women younger than $50 \mathrm{y}$ and have continued to decrease in older women, most likely because of earlier detection, better screening, greater awareness, and more effective treatment options (7). Breast cancer survival rates vary by stage at diagnosis. For patients with localized disease diagnosed early, the overall 5-y survival is $99 \%$. Survival is $85 \%$ for regional disease and $27 \%$ for distant or late-stage disease (5).

\section{TYPES OF BREAST DISEASE AND BREAST TUMORS}

There are 3 different benign breast disease conditions: nonproliferative lesions such as fibrosis, simple cysts, and mild hyperplasia; proliferated lesions without atypia, such as ductal hyperplasia and fibroadenomas; and proliferated lesions with atypia. Examples of proliferated lesions include atypical ductal hyperplasia and atypical lobular hyperplasia. Patients with proliferated lesions have a 4 times higher risk of developing breast cancer (8). These 3 benign breast conditions are most strongly associated with a risk for developing hormone receptor (HR)-positive breast cancers (5).

Although breast cancer is considered a single disease, treating breast cancer can be quite complicated. There are 15 different types of breast cancers, each having its own characteristics, treatment options, and prognosis (Table 1) $(9,10)$. All breast cancers fall into 1 of 2 categories: in situ or invasive. For in situ breast cancer, the abnormal cells originate in a single place. This is considered the earliest form of breast cancer (7). Its main types are ductal carcinoma in situ, in which abnormal cells replace the healthy epithelial cells within the ducts of the breast, and lobular 


\begin{tabular}{|c|c|}
\hline Type & Characteristics \\
\hline Ductal carcinoma in situ & $\begin{array}{l}\text { Noninvasive } B C \text { that starts inside milk ducts, is not life-threatening, and increases risk that } \\
\text { invasive BC will develop }\end{array}$ \\
\hline Invasive ductal carcinoma & Most common type of BC ( $80 \%$ of all cases); more common in women over 55 y old \\
\hline Tubular carcinoma of breast & Small tumors $(\sim \leq 1 \mathrm{~cm})$; low-grade and slow-growing \\
\hline Medullary carcinoma of breast & $\begin{array}{l}\text { Rare; soft, fleshy mass, affecting women in their late } 40 \text { s to early } 50 \text { s; high-grade in } \\
\text { appearance, low-grade in behavior; slow-growing; usually does not spread outside } \\
\text { breast }\end{array}$ \\
\hline $\begin{array}{l}\text { Mucinous carcinoma of breast (also } \\
\text { called colloid carcinoma) }\end{array}$ & $\begin{array}{l}\text { Rare, usually occurring in postmenopausal women; abnormal cells that appear to float in } \\
\text { pools of mucin (a key ingredient in mucus) }\end{array}$ \\
\hline Papillary carcinoma of breast & $\begin{array}{l}\text { Rare, usually occurring in older postmenopausal women; well-defined border; small, } \\
\text { fingerlike projections; often classified as grade } 2\end{array}$ \\
\hline Cribriform carcinoma of breast & $\begin{array}{l}\text { Invasion of breast connective tissues by cancer cells in nestlike formations between ducts } \\
\text { and lobules, creating distinctive holes with Swiss cheese appearance; usually low- } \\
\text { grade }\end{array}$ \\
\hline $\begin{array}{l}\text { Invasive lobular carcinoma (also called } \\
\text { infiltrating lobular carcinoma) }\end{array}$ & $\begin{array}{l}\text { Second most common type of BC ( } 10 \% \text { of all cases of invasive } \mathrm{BC} \text { ); becomes more } \\
\text { common as women grow older (two thirds of cases are in women } 55 \text { y or older) }\end{array}$ \\
\hline Inflammatory BC & $\begin{array}{l}\text { Rare ( } 1 \% \text { of all cases of invasive } \mathrm{BC} \text { ) and aggressive; starts with reddening and swelling of } \\
\text { breast instead of distinct lump; grows and spreads quickly; is more common in black } \\
\text { women and can also affect men }\end{array}$ \\
\hline Lobular carcinoma in situ & $\begin{array}{l}\text { Lobules of abnormal cell growth that increase risk that invasive BC will develop later in life; } \\
\text { occurs in premenopausal women ( } 40-50 \mathrm{y} \text { old }) \text { and is extremely uncommon in men }\end{array}$ \\
\hline Male BC & $\begin{array}{l}\text { Rare ( }<1 \% \text { of all cases of BC; in } 2019, \sim 2,670 \text { men were expected to be diagnosed with } \\
\text { BC) }\end{array}$ \\
\hline $\begin{array}{l}\text { Molecular subtypes of } \mathrm{BC} \text {, based on } \\
\text { the genes expressed }\end{array}$ & Luminal A, luminal B, triple-negative, and HER2-enriched (Table 2) \\
\hline Paget disease of nipple & $\begin{array}{l}\text { Rare ( }<5 \% \text { of all BC cases in United States); cells collect in or around nipple; } 97 \% \text { of } \\
\text { patients also have cancer elsewhere in breast (ductal carcinoma in situ or invasive } \\
\text { cancer); unusual changes in nipple and areola are often first indication that BC is } \\
\text { present }\end{array}$ \\
\hline Phyllodes tumors of breast & $\begin{array}{l}\text { Rare ( }<1 \% \text { of all breast tumors); called phyllodes ("leaflike," in Greek) because tumor cells } \\
\text { grow in leaflike pattern; tends to grow quickly; rarely spreads outside breast }\end{array}$ \\
\hline Metastatic (stage IV) BC & $\begin{array}{l}\text { Spread of cancer to liver, brain, bones, or lungs; will occur in } 30 \% \text { of women diagnosed } \\
\text { with early-stage BC (if in bone, metastatic tumor comprises BC cells, not bone cells) }\end{array}$ \\
\hline
\end{tabular}

carcinoma in situ, in which abnormal cells grow within and expand the lobules of the breast (5). Invasive breast cancers are defined as breast tumors that have broken through the walls of the glands and ducts where they originated and grown into surrounding breast tissue (5). Invasive breast cancer represents over $80 \%$ of all breast cancers (5) and, although considered a single disease, can be complicated and challenging to treat. There are 21 distant histologic subtypes and 4 different molecular subtypes of breast cancer, each of which is very different in terms of risk factors, presentation, response to therapy, and outcomes (5). There are 2 types of HRs_-ER and progesterone receptor (PR)as well as a growth-promoting protein called human epidermal growth factor receptor 2 (HER2). This growth factor receptor can be positive or negative (HER2+ or HER2-), and a patient can also have extra copies of the HER2 gene (5). These routinely used biologic markers $(\mathrm{ER}+, \mathrm{ER}-, \mathrm{PR}+, \mathrm{PR}-, \mathrm{HER} 2+$, and HER2-) help approximate the molecular subtype of breast cancer (5). Table 2 explains the 4 main molecular subtypes to help the reader better understand the importance they play in determining a patient's course of therapy, prognosis, and outcome.

\section{BREAST CANCER STAGING}

Once breast cancer is suspected, it is essential to analyze the breast tissue in order to confirm the diagnosis and determine the extent or stage. Typical ways to analyze the tumor tissue are needle biopsy or surgical incision. Cells from the specimen are examined under a microscope by a pathologist using immunohistochemical assay techniques. It is also important to stage the breast cancer. The stage of the disease, when first diagnosed, correlates directly with prognosis and outcome (5). The stage, grade, and type of breast cancer are critical information for determining the treatment.

The grade of a tumor differs from the stage of a tumor, but both the stage and the grade are determined after the tumor is surgically removed and analyzed. In the Nottingham grading system (Table 3$)$ (11), breast tumors are classified as grade 1,2 , or 3 . Three characteristics are analyzed to determine the grade of a tumor: tubule formation, nuclear grade, and mitotic rate (11). Tubule formation refers to the amount of tumor tissue that consists of normal breast (milk) duct structures. Nuclear grade refers to the size and shape of the nucleus in the tumor cells. Mitotic rate refers to the number of dividing cells; it is a measure of 
TABLE 2

The 4 Main Molecular Subtypes of Breast Cancer*

\begin{tabular}{|c|c|c|c|c|}
\hline Type & Expression & Characteristics & Prognosis & Therapy \\
\hline Luminal A & $\mathrm{HR}+/ \mathrm{HER} 2-$ & $\begin{array}{l}\text { Slow-growing, less aggressive } \\
\text { than other subtypes }\end{array}$ & $\begin{array}{l}\text { Favorable prognosis, } \\
\text { particularly in short } \\
\text { term }\end{array}$ & Antihormone therapy \\
\hline Luminal B & $\mathrm{HR}+/ \mathrm{HER} 2+$ & $\begin{array}{l}\text { Highly positive for Ki-67 } \\
\text { (indicator of large } \\
\text { proportion of actively } \\
\text { dividing cells) or HER2; } \\
\text { tends to be higher-grade }\end{array}$ & $\begin{array}{l}\text { Poorer survival than for } \\
\text { luminal A cancers }\end{array}$ & $\begin{array}{l}\text { Chemotherapy, } \\
\text { hormone therapy, } \\
\text { and treatments } \\
\text { targeting HER2 } \\
\text { receptor }\end{array}$ \\
\hline Triple-negative & $\begin{array}{l}\text { HR-/HER2- } \\
\quad(\mathrm{ER}-, \mathrm{PR}-\text {, and HER2-) }\end{array}$ & $\begin{array}{l}\text { Twice as common in black } \\
\text { women as in white women } \\
\text { in United States; more } \\
\text { common in premenopausal } \\
\text { women and those with } \\
\text { BRCA1 gene mutation }\end{array}$ & $\begin{array}{l}\text { Poorer short-term } \\
\text { prognosis than for } \\
\text { other subtypes }\end{array}$ & $\begin{array}{l}\text { No current targeted } \\
\text { therapy }\end{array}$ \\
\hline HER2-enriched & HR-/HER2+ & $\begin{array}{l}\text { Grows and spreads more } \\
\text { aggressively than other } \\
\text { subtypes }\end{array}$ & $\begin{array}{l}\text { Poorer short-term } \\
\text { prognosis than for } \\
\text { HR+ breast cancers; } \\
\text { recent widespread use } \\
\text { of targeted therapies } \\
\text { for HER } 2+ \\
\text { cancers has improved } \\
\text { outcomes }\end{array}$ & $\begin{array}{l}\text { Combination of } \\
\text { surgery, radiation } \\
\text { therapy, } \\
\text { chemotherapy, or } \\
\text { targeted therapy } \\
\text { such as the immune } \\
\text { monoclonal antibody } \\
\text { trastuzumab }\end{array}$ \\
\hline
\end{tabular}

${ }^{*}$ The different subtypes differ in risk factors, presentation, response to treatment, and outcome. Techniques to profile tumor gene expression allow better understanding of subtypes but are costly and complex. Subtypes are approximated using biologic markers, including presence or absence of ER or PR and excess levels of HER2 or extra copies of HER2 gene (HER2+/HER2-) $(5,48)$.

how fast the tumor cells are growing and dividing. A point system is then used to evaluate these 3 characteristics: 1 point is assigned if the cells and tumor tissue look the

TABLE 3

Nottingham Grading System

\begin{tabular}{|c|c|}
\hline Parameter & Description \\
\hline \multicolumn{2}{|l|}{ Characteristic } \\
\hline Tubule formation & $\begin{array}{l}\text { Amount of tumor tissue with normal } \\
\text { breast (milk) duct structures }\end{array}$ \\
\hline Nuclear grade & $\begin{array}{l}\text { Size and shape of nucleus in tumor } \\
\text { cells }\end{array}$ \\
\hline Mitotic rate & $\begin{array}{l}\text { Number of dividing cells (measure of } \\
\text { how fast tumor cells grow and } \\
\text { divide) }\end{array}$ \\
\hline \multicolumn{2}{|l|}{ Points* } \\
\hline 1 & $\begin{array}{l}\text { Cells and tumor tissue look most } \\
\text { normal }\end{array}$ \\
\hline 3 & $\begin{array}{l}\text { Cells and tumor tissue look most } \\
\text { abnormal }\end{array}$ \\
\hline \multicolumn{2}{|l|}{ Grade } \\
\hline 1 (3-5 total points) & $\begin{array}{l}\text { Low (well differentiated; slower } \\
\text { growing, less likely to spread) }\end{array}$ \\
\hline 2 (6-7 total points) & $\begin{array}{l}\text { Intermediate (moderately } \\
\text { differentiated) }\end{array}$ \\
\hline 3 (8-9 total points) & $\begin{array}{l}\text { High (poorly differentiated; faster } \\
\text { growing, more likely to spread) }\end{array}$ \\
\hline
\end{tabular}

*Points are assigned to tumor for the 3 characteristics. Total score ranges from 3 to 9 , corresponding to grade 1,2 , or $3(11,49)$. most normal, and 3 points are assigned if the cells and tissue look the most abnormal (11). The total score for the 3 characteristics is then determined, ranging from 3 to 9 points. A grade 1 tumor (3-5 points) is considered to be of low grade (well-differentiated), slow-growing, and less likely to spread (11); a grade 2 tumor (6-7 points) is considered to be of intermediate grade (moderately differentiated); and a grade 3 tumor (8-9 points) is considered to be of high grade (well-differentiated), fast-growing, and more likely to spread (11).

There are 2 main staging systems: the TNM system (the system of the American Joint Committee on Cancer Staging) (12) and the Surveillance, Epidemiology, and End Results (SEER) system (5). The TNM system evaluates the tumor (T) and how far cancer has spread within the breast and to adjacent tissues, the extent of spread to nearby lymph nodes $(\mathrm{N})$, and the presence or absence of distant metastasis (M). It is most commonly used in a clinical setting (5). Once the T, N, and $\mathrm{M}$ have been determined, a stage of 0 , I, II, III, or IV can be assigned. Stage 0 is the earliest stage of breast cancer, and stage IV is the most advanced stage. The SEER system is more simplified than the TNM system and is commonly used for reporting cancer registry data and for public health research and planning (5). The SEER system has 4 stages: the in situ stage, the local stage, the regional stage, and the distant stage. The in situ stage corresponds to stage 0 in the TNM system and is when abnormal cells have not invaded nearby tissues. The local stage corresponds to stage I and some stage II cancers 
in the TNM system and is when cancers are confined to the breast. The regional stage is when tumors have spread to surrounding tissue or nearby lymph nodes and generally corresponds to stage II or III in the TNM system, depending on tumor size and lymph node involvement (5). The distant stage is when cancers have metastasized to distant organs or lymph nodes above the collarbone and corresponds to some stage IIIc and all stage IV cancers in the TNM system (5).

\section{BREAST CANCER TREATMENT OPTIONS}

There are many breast cancer treatment options. Choosing the right option depends on multiple factors, such as the stage, grade, and molecular subtype of the patient's tumor, as well as its unique HR status (Table 4) (5).

\section{IMAGING MODALITIES FOR BREAST CANCER}

Several different imaging modalities can be used when looking for breast cancer. Mammography is the most common and is considered the gold standard for general screening and for detecting early-stage breast cancer (13). Mammography uses low-dose $\mathrm{x}$-rays to image human breast tissue. Calcifications, or calcium deposits, as well as cancerous masses, can be seen on mammography as bright spots, usually before a mass becomes palpable (14). Over the years, the way mammography images are acquired has changed from direct-exposure mammography (1930s to mid-1960s) to xeromammography (1970s) to screen-film mammography (1980s-1990s), which used breast compression and a more collimated x-ray beam, resulting in decreased imaging times, reduced dose, and increased contrast in the image (14). Screen-film mammography eventually completely replaced direct-exposure mammography and xeromammography (14). Today, there are 3 types of mammography: screen-film mammography, 2-dimensional digital mammography, and 3-dimensional digital mammography; the latter two are also called digital breast tomosynthesis (5). There is also another relatively new technique (implemented initially at the Mayo Clinic in 2015) called contrasted-enhanced mammography, which assesses the neovascularity of the breast similarly to MRI (15). Neovascularization is the proliferation of blood vessels in a tissue not normally containing them or the proliferation of blood vessels of a type different from what is usual in a tissue (16).

Although mammography has decreased mortality rates by as much as $30 \%$ over the years (13), it still has some shortcomings in certain situations. It is not very sensitive in detecting cancer in patients with dense breasts (13). Sensitivity is the ability of a test to detect disease when the disease is present, and specificity is the ability of a test to rule out disease when the disease is truly absent. As sensitivity increases, specificity decreases, and vice versa $(17,18)$. The overall sensitivity and specificity of mammography in patients aged 40 y or younger are $76 \%$ and $87 \%$, respectively (19); in comparison, the sensitivity and specificity in women aged $75-79$ y are $88 \%$ and $93 \%$, respectively (19). The sensitivity for detecting breast cancer on mammography increases as the patient grows older. In patients with dense breasts, the sensitivity of mammography decreases to between $47.8 \%$ and $64.4 \%$ (20). The accuracy of mammography is high for basic breast cancer screening in women, but unfortunately, accuracy is reduced in high-risk patients and women with dense breast tissue (19). When breast ultrasound is used in addition to mammography, the sensitivity increases to $94.6 \%$ (13).

Ultrasound is another useful imaging modality to help image the breast. Breast ultrasound is typically used as an adjunct to mammography, helping to further characterize suspected lesions such as solid tumors (e.g., benign fibroadenoma or cancer) or fluid-filled lesions (e.g., benign cyst) found on mammography (21). Breast ultrasound tends to be

TABLE 4

Breast Cancer Treatment Options

\begin{tabular}{|c|c|c|}
\hline \multirow{2}{*}{ Treatment options } & \multicolumn{2}{|c|}{ Invasive BC by stage } \\
\hline & Stage & Treatment option \\
\hline $\begin{array}{l}\text { 1. BCS alone } \\
\text { 2. BCS + RT }\end{array}$ & Stages I and II & $\begin{array}{l}\mathrm{BCS}+\mathrm{RT}(34 \%) \\
\mathrm{BCS}+\mathrm{RT}+\text { chemo (17\%) }\end{array}$ \\
\hline $\begin{array}{l}\text { 3. } \mathrm{BCS}+\mathrm{RT}+\text { chemo } \\
\text { 4. BCS + chemo }\end{array}$ & & $\begin{array}{l}\text { Mastectomy alone (17\%) } \\
\text { Mastectomy + chemo (12\%) }\end{array}$ \\
\hline $\begin{array}{l}\text { 5. Mastectomy alone } \\
\text { 6. Mastectomy + RT }\end{array}$ & Stage III & $\begin{array}{l}\text { Mastectomy + RT + chemo }(48 \%) \\
\text { BCS + RT + chemo }(15 \%)\end{array}$ \\
\hline $\begin{array}{l}\text { 7. Mastectomy }+ \text { chemo } \\
\text { 8. Mastectomy }+\mathrm{RT}+\text { chemo }\end{array}$ & & $\begin{array}{l}\text { Mastectomy + chemo (13\%) } \\
\text { Mastectomy alone }(7 \%)\end{array}$ \\
\hline \multirow[t]{2}{*}{$\begin{array}{l}\text { 9. RT or chemo } \\
\text { 10. No surgery, RT, or chemo }\end{array}$} & Stage IV & $\begin{array}{l}\text { RT or chemo }(48 \%) \\
\text { No surgery, RT, or chemo }(21 \%)\end{array}$ \\
\hline & & $\begin{array}{l}\text { Mastectomy + RT + chemo }(7 \%) \\
\text { Mastectomy + chemo }(7 \%)\end{array}$ \\
\hline
\end{tabular}

BCS = breast-conserving surgery; RT = radiation therapy; chemo = chemotherapy, including targeted therapy and immunotherapy drugs.

Source: (5). 


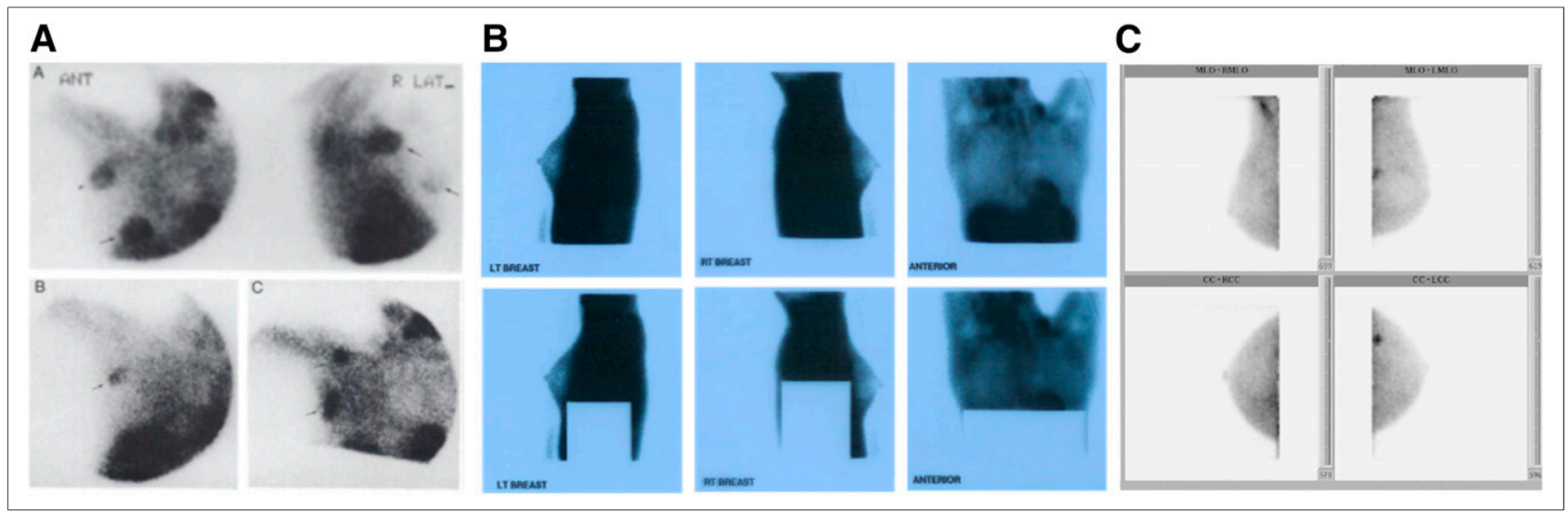

FIGURE 2. (A) Thallium images of breast from early 1990s (45). (B) Scintimammography images from 1998. (Courtesy of Union Hospital, Elkton, MD.) (C) ${ }^{99 m T c-s e s t a m i b i ~ m o l e c u l a r ~ b r e a s t ~ i m a g e s ~ f r o m ~} 2012$ (46).

used more in younger women because their breasts are usually denser, whereas older women's breasts tend to be fattier. Other benefits of breast ultrasound is that there is no radiation, it is inexpensive, and it can be used by radiologists or breast surgeons to help locate tumors during fineneedle or core biopsy procedures. There are some limitations to breast ultrasound. It cannot determine whether a solid lump is cancerous or benign, nor can it detect calcifications; thus, there may be many false-positive ultrasound results, which sometimes result in unnecessary biopsies (21). The sensitivity for mammography with adjunctive breast ultrasound were $97.3 \%$, versus $74.7 \%$ for mammography alone. In particular, the sensitivity of mammography in women with very dense breasts (category 4 in the Breast Imaging Reporting and Database System) was $47.6 \%$, which increased to $76.1 \%$ when ultrasound screening was added (20).

MRI is another imaging modality used in high-risk breast cancer patients. A study by Warner et al. (22) showed that among carriers of the BRCA1 or BRCA2 mutation, annual MRI screening resulted in a $70 \%$ reduction of developing stage II-IV invasive breast cancers, compared with no annual MRI examination (22). Although MRI is more expensive than other breast imaging modalities, there are many benefits to its use in high-risk patients, including a sensitivity of approximately 95\%, excellent image resolution, and the ability to simultaneously evaluate both breasts.
MRI is also useful for evaluating dense breasts with an inverted nipple and helps determine whether a lumpectomy or mastectomy is the best treatment (19). Other benefits of breast MRI include no radiation exposure and the ability to view images in multiple planes (19). Unfortunately, there are some disadvantages as well, including the high cost of the procedure compared with mammography and ultrasound and the potential for an adverse reaction to the injected contrast medium (19).

\section{NUCLEAR MEDICINE AND MOLECULAR BREAST IMAGING...A LOOK BACK}

Planar nuclear medicine lbreast imaging began almost 25 y ago (May 1997), when 99mTc-sestamibi (Miraluma; Bristol-Myers Squibb) was approved by the Food and Drug Administration (FDA) for breast imaging (23). In 1997, nuclear medicine breast imaging was called scintimammography. Over the years, nuclear medicine camera technology improved, new breast-specific $\gamma$-cameras were developed, and scintimammography became known as molecular breast imaging (Fig. 2). Molecular breast imaging provides high-resolution images with the ability to detect tumors smaller than $1 \mathrm{~cm}$. It is also used to evaluate for occult breast cancer in women at high risk, with a sensitivity of about $96 \%$ and a specificity of about $60 \%$ (13). Another benefit of molecular breast imaging with ${ }^{99 \mathrm{~m} T c-s e s t a m i b i}$ is no need to compress the breast as is done in mam-

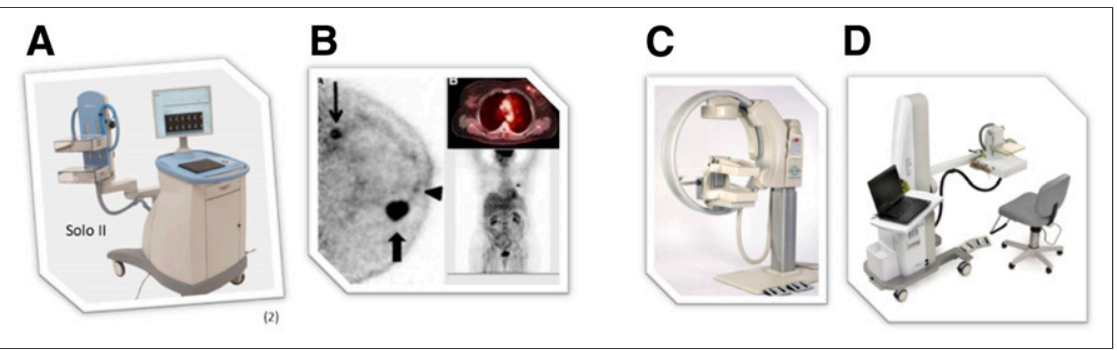

FIGURE 3. (A and B) Solo II (CMR Naviscan) PET-specific breast scanner (A) and PET mammography images obtained with it (B). (C and D) Two breast-specific $y$ cameras: LumaGEM (CMR Naviscan) (C) and Ergo (Digirad) (D) (All images courtesy of the manufacturers.) mography.

Nuclear medicine breast imaging continued to improve over time, culminating in the use of ${ }^{18} \mathrm{~F}$-FDG PET, or positron emission mammography, for this purpose (Fig. 3). This modality produces good contrast between cancerous and healthy cells and provides information about the chemical function of other organs and tissue in the body (13). PET is useful for detecting and staging recurrent breast cancer and for assessing its response to 


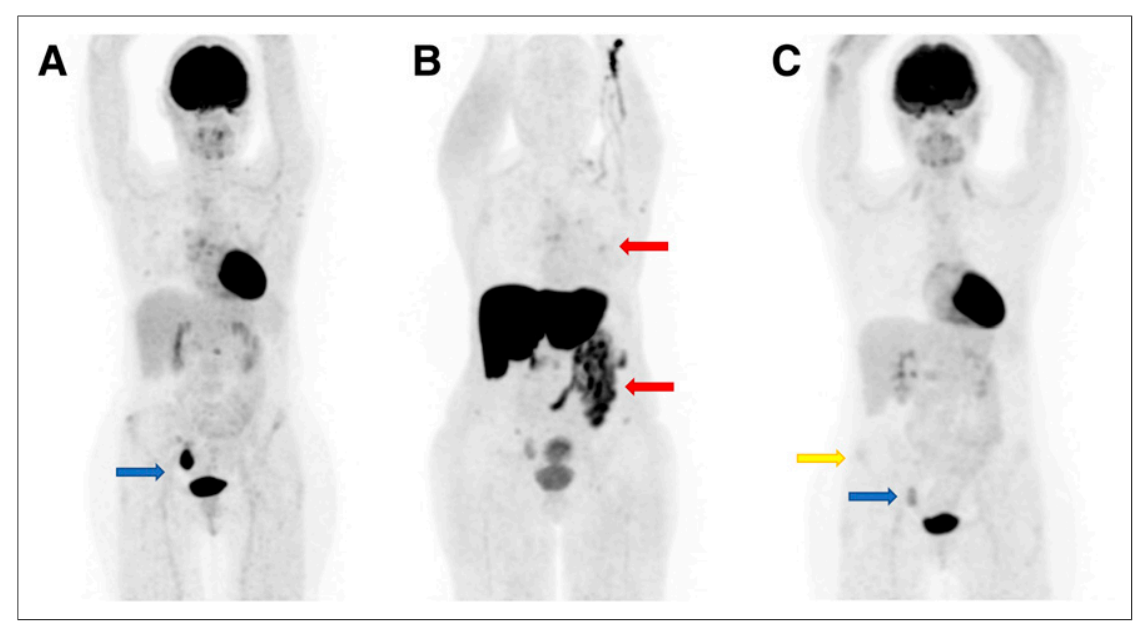

FIGURE 4. ${ }^{18} \mathrm{~F}$-fluoroestradiol case review 1. (A) Second ${ }^{18} \mathrm{~F}-\mathrm{FDG}$ PET/CT study, 8 mo after treatment switch (from original treatment to new treatment), showing uptake in right ovary (arrow). (B) ${ }^{18} \mathrm{~F}$-fluoroestradiol PET/CT $15 \mathrm{~d}$ after second ${ }^{18} \mathrm{~F}-\mathrm{FDG} \mathrm{PET} /$ CT study, showing expression of ERs by all lesions as indicated by ${ }^{18} \mathrm{~F}$-fluoroestradiol uptake in chest and abdomen (arrows). (C) ${ }^{18} \mathrm{~F}-\mathrm{FDG}$ PET/CT study 4 mo after initiation of fulvestrant hormone therapy (selective ER degrader that blocks and damages ERs), showing increase in ovarian uptake and emergence of bone uptake. Findings on second ${ }^{18} \mathrm{~F}-\mathrm{FDG}$ scan $(\mathrm{A})$ prompted question of whether ovarian primary cancer was present and whether hormone therapy would help. Biopsy of bone (yellow arrow) and ovarian (blue arrow) lesions was difficult. Bone lesion biopsy was noncontributory. (Courtesy of Zionexa.)

chemotherapy and is more accurate than MRI in predicting a pathologic nonresponse to therapy (13).

\section{NUCLEAR MEDICINE AND MOLECULAR BREAST IMAGING...A LOOK AHEAD}

A novel PET imaging agent called ${ }^{18} \mathrm{~F}$-fluoroestradiol is another possible breast imaging agent that is showing promise in noninvasively evaluating the ER status of patients with primary and metastatic breast cancer. ${ }^{18} \mathrm{~F}$-fluoroestradiol has a $60 \%-100 \%$ relative binding affinity for the ER, making it an excellent tracer to image ERs throughout the body (24). ${ }^{18} \mathrm{~F}-$ fluoroestradiol is currently approved in France under the trade name EstroTep (25) but is not currently FDA-approved in the United States. However, it has been used in research for many years in the United States, Canada, Europe, and Asia (26).

The treatment and prognosis for breast cancer depend on whether the clinical molecular subtype of a patient's tumor is $\mathrm{HR}+, \mathrm{HR}-, \mathrm{HER} 2+$, or HER2 - (Table 2) (5). Among the HR + tumors, ER + tumors are the most prevalent type, representing approximately $75 \%-80 \%$ of all breast tumors (5). ${ }^{18} \mathrm{~F}$-fluoroestradiol imaging might become a diagnostic imaging tool to help accurately identify ER + tumor cells throughout the body. Knowing a patient's ER status helps medical oncologists better understand each case of breast cancer and its best course of therapy.

Currently, the only way to assess the ER status of a primary breast tumor or metastatic lesions is through the use of conventional in vitro immunohistochemical assays at biopsy or on resected tumors (26). Because of the affinity of ${ }^{18} \mathrm{~F}$-fluoroestradiol to ERs, it can provide a noninvasive, in vivo way to evaluate ER expression by identifying ER + tumor cells throughout the body, as indicated by increased uptake on ${ }^{18} \mathrm{~F}$-fluoroestradiol PET images. Medical oncologists must keep in mind that the HR status of the primary tumor does not necessarily predict the HR status of metastatic lesions. A primary tumor may be heterotypical, having both ER+ and ER - receptors instead of a single type. HR genes may be downregulated or lost in metastatic lesions (27), complicating the accuracy of treatment decisions. One treatment option might work for the ER+ primary tumor but not for a metastatic lesion whose receptor has become downregulated or lost and is now ER-. Lindstrom et al. (2012) noted the importance of being aware that, in about a third of patients, the ER status after recurrence or progression may differ from that of the primary tumor and that a change from ER + to ER - is associated with a $48 \%$ increase in mortality, as compared with no change (27). The ability to predict a therapeutic response in distant lesions is critical in planning the treatment approach for metastatic disease. Imaging of ERs with ${ }^{18} \mathrm{~F}$-fluoroestradiol PET is like performing a noninvasive whole-body biopsy, in that all ER+ lesions throughout the body can be visualized on the scan. Most importantly, ${ }^{18} \mathrm{~F}$-fluoroestradiol PET correlates well with immunohistochemical results and might be able to predict a patient's response to endocrine therapy $(26,28)$.

\section{${ }^{18}$ F-FLUOROESTRADIOL PET BASICS}

Because ${ }^{18} \mathrm{~F}$-fluoroestradiol is not an FDA-approved product, no imaging protocol has been approved by the FDA for general use. This article therefore provides only basic information from a research perspective. If ${ }^{18} \mathrm{~F}$-fluoroestradiol becomes FDA-approved, the prescribing information, contraindications, and prep instructions in the package insert should be followed regardless of what is written in this article.

A dose of $111-222 \mathrm{MBq}(3-6 \mathrm{mCi})$ of ${ }^{18} \mathrm{~F}$-fluoroestradiol is intravenously injected over 2 min, and scanning typically follows 30-90 min afterward $(29,30)$. Because ${ }^{18} \mathrm{~F}$-fluoroestradiol is not glucose-dependent, light, noise, and sound do not affect uptake of the tracer after it is injected. As with all PET procedures, hydration and frequent voiding are suggested to help decrease radiation exposure. The acquisition parameters vary from 3 min per bed position from the thighs to the skull (29) to dynamic imaging for $60 \mathrm{~min}$ (31). Peterson et al. (31) acquired a dynamic scan over a single apparent field of view at the time of 


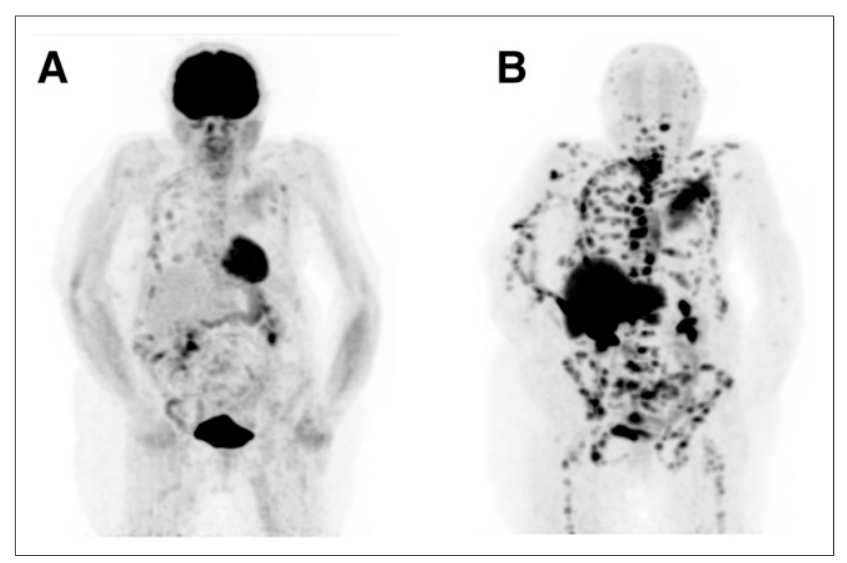

FIGURE 5. ${ }^{18} \mathrm{~F}$-fluoroestradiol case review 2. Patient had ER+, HER2-, T2NOMO lobular carcinoma of left breast, which was treated with neoadjuvant chemotherapy, surgery, adjuvant chemotherapy, radiation therapy, and (for 5 y) tamoxifen hormone therapy. Eight years after total treatment completion (chemotherapy, surgery, radiation, and tamoxifen), vertebral fractures of T10 and T12 emerged, and cancer antigen 15-3 level was 3,500 U/mL (reference value, $<25 \mathrm{U} / \mathrm{mL}$ ). (A) ${ }^{18} \mathrm{~F}-\mathrm{FDG} P E T / C T$ study showing that some lesions were barely seen with ${ }^{18} \mathrm{~F}-\mathrm{FDG}$. (B) ${ }^{18} \mathrm{~F}$-fluoroestradiol PET/ CT study $1 \mathrm{~d}$ after ${ }^{18} \mathrm{~F}-\mathrm{FDG}$ PET/CT study, showing that all lesions expressed ERs and that accumulation of ${ }^{18} \mathrm{~F}$-fluoroestradiol was higher than that of ${ }^{18} \mathrm{~F}-\mathrm{FDG}$, probably because of lobular histology. Patient was subsequently treated with aromatase inhibitor (exemestane), resulting in lesion stabilization and cancer antigen $15-3$ reduction to $150 \mathrm{U} / \mathrm{mL} 2$ y after beginning treatment. (Courtesy of Zionexa.)

injection, with the location to be scanned being determined by the principal investigator using prior imaging (CT and ${ }^{18}$ F-FDG PET).

${ }^{18} \mathrm{~F}$-fluoroestradiol is rapidly metabolized in the liver; at 120 min after injection, only $10 \%$ of the injected dose remains unmetabolized (26). ${ }^{18} \mathrm{~F}$-fluoroestradiol excretion is primarily biliary and urinary, with the critical organ being the liver, which receives $0.13 \mathrm{mGy} / \mathrm{MBq}$, or $28 \mathrm{mGy}$, of exposure $(26,32)$. The effective dose equivalent for ${ }^{18} \mathrm{~F}$-fluoroestradiol is $0.022 \mathrm{mSv} / \mathrm{MBq}(32)$.

Low estrogen levels will result in no or low uptake of ${ }^{18} \mathrm{~F}$-fluoroestradiol (33). Aromatase inhibitors and hormone therapy block ERs, causing the ${ }^{18} \mathrm{~F}$-fluoroestradiol PET signal to decrease or disappear (33). Selective ER modulators (such as tamoxifen) block ERs, and selective ER degraders (such as fulvestrant) block and damage ERs (33). Figures 4-6 present case studies for 3 patients who underwent imaging with ${ }^{18} \mathrm{~F}$-fluoroestradiol.

\section{CURRENT TREATMENT OPTIONS FOR ER+ AND ER- PATIENTS}

The current treatment option for patients with ER+ sites is to halt tumor growth using endocrine or hormone therapy, typically ER modulators such as tamoxifen. Selective downregulators such as fulvestrant can also be used, as well as aromatase inhibitors such as anastrozole (5). These hormone therapy drugs work by blocking ERs from taking up estrogen, which is what the cancerous tumor uses to grow. If there is no estrogen, the tumor will not grow. Patients with ER - tumors will not respond to hormone therapy (5).

Metastatic breast cancer has its own set of guidelines on the best treatment options based on the recommendations of the National Comprehensive Cancer Network. Depending on menopausal status and treatment his-

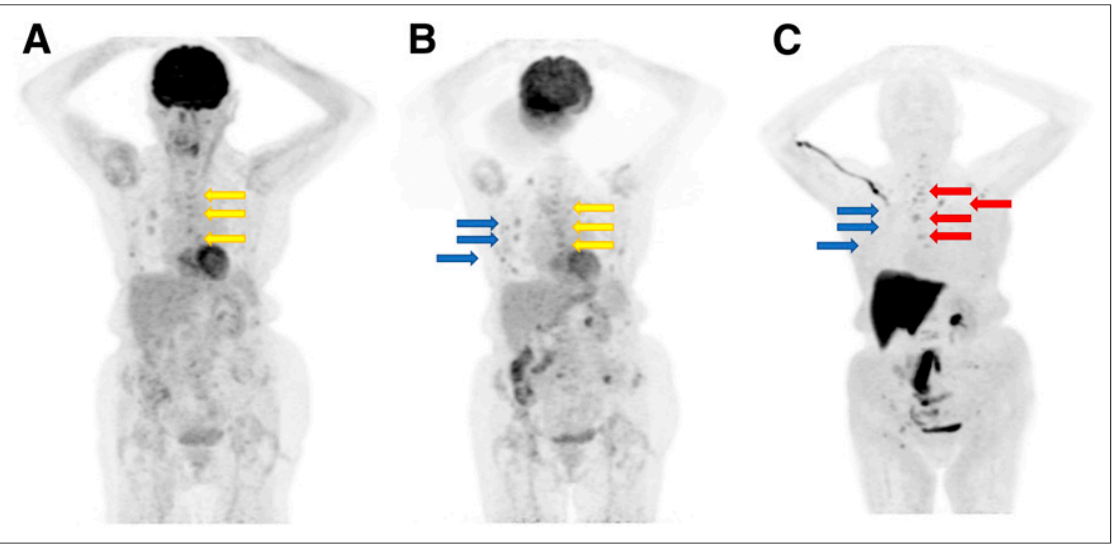

FIGURE 6. ${ }^{18} \mathrm{~F}$-fluoroestradiol case review 3. Patient had ER+, PR-, HER2- lobular carcinoma with initial bone metastases. (A) First ${ }^{18} \mathrm{~F}-\mathrm{FDG}$ PET/CT study, showing lesions (arrows) that later showed progression. (B) Second ${ }^{18} \mathrm{~F}-\mathrm{FDG}$ PET/CT study, showing progression of previously seen lesions (yellow arrows) and uptake in lesions that were subsequently negative for ${ }^{18} \mathrm{~F}$-fluoroestradiol (blue arrows). (C) ${ }^{18} \mathrm{~F}$-fluoroestradiol PET/CT study 1 mo after second ${ }^{18}$ F-FDG PET/CT study, showing ${ }^{18}$ F-fluoroestradiol-positive lesions (red arrows) corresponding to progressive lesions seen with ${ }^{18} \mathrm{~F}-\mathrm{FDG}$, but no uptake (blue arrows) where uptake was seen on second ${ }^{18} \mathrm{~F}$-FDG PET/CT study. ${ }^{18} \mathrm{~F}$ fluoroestradiol-positive lesions correspond to progressive lesions seen with ${ }^{18} \mathrm{~F}-\mathrm{FDG}$ (yellow arrows). Treatment with aromatase inhibitor (which blocks ERs) resulted in reduction or disappearance of ${ }^{18} \mathrm{~F}$-fluoroestradiol tracer uptake. Radiation therapy was performed on T9 and left iliac bone. Exemestane treatment resulted in bone progression in L5 and left iliac bone. (Courtesy of Zionexa.) tory, the current treatment options for metastatic breast cancer include aromatase inhibitors, tamoxifen, fulvestrant, selective ER modulators, and selective ER down-regulators (34). These options also apply to patients who have $\mathrm{PR}+$ tumors (35). These options are not for patients with ER - or PR - tumors (35).

\section{POTENTIAL BENEFITS OF ${ }^{18}$ F-FLUOROESTRADIOL PET}

There are many potential benefits of imaging with ${ }^{18} \mathrm{~F}$-fluoroestradiol PET. It can be used when lesions are inaccessible or otherwise challenging to biopsy, when suspicion of cancer is insufficient to justify an invasive procedure, when the tumor pathology is aggressive, or when a patient refuses to undergo the biopsy procedure. ${ }^{18} \mathrm{~F}$ fluoroestradiol PET can also evaluate potential disease heterogeneity. A study by Yang et al. (35) showed that 37.5\% 
TABLE 5

Molecular Imaging Versus Biopsy

\begin{tabular}{cc}
\hline $\begin{array}{c}\text { Benefits of molecular } \\
\text { imaging }\end{array}$ & $\begin{array}{c}\text { Limitations and risks of } \\
\text { biopsy }\end{array}$ \\
\hline $\begin{array}{c}\text { Stages cancer } \\
\text { Predicts response to } \\
\text { therapy }\end{array}$ & $\begin{array}{c}\text { Is invasive } \\
\text { Is restricted to accessible } \\
\text { lesions }\end{array}$ \\
$\begin{array}{c}\text { Monitors and evaluates } \\
\text { therapeutic benefit }\end{array}$ & $\begin{array}{c}\text { Has limited ability to be } \\
\text { repeated }\end{array}$ \\
$\begin{array}{c}\text { Advances personalized } \\
\text { medicine and targeted } \\
\text { therapy }\end{array}$ & $\begin{array}{c}\text { Has risk of disseminating } \\
\text { tumor cells }\end{array}$ \\
$\begin{array}{c}\text { Images a specific } \\
\text { biomarker (ER) }\end{array}$ & \\
Has shorter image & \\
acquisition time & \\
\hline
\end{tabular}

of metastatic breast cancer patients had a heterogeneous pattern of both ER+ and ER - lesions (28). Evaluating all lesions for their ER status is a critical step in determining the appropriate treatment option, helping improve the overall response to therapy and a patient's outcome and ultimate survival. Breast imaging with ${ }^{18} \mathrm{~F}$-fluoroestradiol PET can complement a patient's biopsy and can noninvasively evaluate multiple areas of the body, including organs such as the brain, which standard ${ }^{18} \mathrm{~F}$ FDG whole-body PET cannot do. Table 5 outlines the benefits of molecular imaging versus the limitations and risks of biopsy. Although ${ }^{18} \mathrm{~F}$-fluoroestradiol PET has many benefits, it does have some limitations. For example, its ability to detect liver metastases is limited by normal-liver uptake due to increased hepatic metabolism (26). The considerable enterohepatic circulation of ${ }^{18} \mathrm{~F}$-fluoroestradiol can also complicate abdominal imaging (26).

The Allred score is a measure of the percentage of cells in an immunohistochemically stained biopsy sample that test positive for HRs and how well the receptors show up after staining. This information is combined to score the sample on a scale from 0 to 8 . A higher score indicates that more receptors were found and that they were easier to see in the sample. (36). From a treatment standpoint, if a patient's Allred score is 0, hormonal therapy generally will not be helpful in treating that patient's breast cancer. When the score is 0 , the cancer is considered HR- $(36) .{ }^{18} \mathrm{~F}$ fluoroestradiol has a high sensitivity and specificity for detecting ER + lesions, as was illustrated in a metaanalysis of 12 studies (Table 6 ) that evaluated ${ }^{18} \mathrm{~F}$-fluoroestradiol PET in breast cancer patients and compared the results with the Allred score (4,29-31,36-43). The metaanalysis demonstrated a sensitivity of $100 \%$ and specificity of $99 \%$ for metastatic lesions. When the primary lesion and metastatic lesions were combined, fluoroestradiol imaging resulted in a sensitivity of $81 \%$ and a specificity of $80 \%$, compared with the Allred score (30-32,37-45). The results of the metaanalysis were similar to those for 2 other metaanalyses, performed by van Kruchten et al. (24) and Evangelista et al. (44).

TABLE 6

Diagnostic Performance of ${ }^{18} \mathrm{~F}$-Fluoroestradiol PET Versus Immunohistochemistry in 12 Studies

\begin{tabular}{|c|c|c|c|c|c|}
\hline Study & $n$ & Sensitivity & Specificity & $\begin{array}{c}\text { Definition of ER+ } \\
\text { IHC }\end{array}$ & PET \\
\hline \multicolumn{6}{|l|}{ Peterson (31) } \\
\hline Nonbreast & 10 & $0.99(0.67-1)$ & $0.96(0.33-1)$ & Allred score $>2$ & SUV $_{\text {mean }}>1.5$ \\
\hline Breast & 4 & $0.98(0.50-1)$ & Indeterminate & Allred score $>2$ & $\mathrm{SUV}_{\text {mean }}>1.5$ \\
\hline Venema (37) & 13 & $0.99(0.73-1)$ & $0.96(0.33-1)$ & $\geq 1 \%$ of cells & SUV $_{\max }>1.5$ \\
\hline Gemignani (29) & 48 & $0.85(0.71-0.93)$ & $0.74(0.41-0.93)$ & $\geq 1 \%$ of cells & $\mathrm{SUV}_{\text {mean }}>1.5$ \\
\hline Yang (35) & 18 & $0.99(0.73-1)$ & $0.85(0.48-0.97)$ & $\geq 1 \%$ of cells & $\mathrm{SUV}_{\max }>1.5$ \\
\hline \multicolumn{6}{|l|}{ Peterson (38) } \\
\hline Nonbreast & 3 & $0.97(0.43-1)$ & $0.96(0.33-1)$ & $\geq 5 \%$ of cells & $\mathrm{SUV}_{\text {mean }}>1$ \\
\hline Breast & 9 & $0.99(0.69-1)$ & $0.66(0.21-0.93)$ & $\geq 5 \%$ of cells & SUV $_{\text {mean }}>1$ \\
\hline \multicolumn{6}{|l|}{ Gupta (39) } \\
\hline Nonbreast & 4 & $0.98(0.50-1)$ & Indeterminate & All ER + were $\geq 15 \%$ of cells & Qualitative \\
\hline Breast & 6 & $0.98(0.60-1)$ & Indeterminate & & \\
\hline Unclear location & 2 & & & & \\
\hline Chae $(40)$ & 85 & $0.77(0.63-0.86)$ & $1.00(0.90-1)$ & Allred score $\geq 3$ & Qualitative \\
\hline Chae (30) & 24 & $0.92(0.75-0.98)$ & Indeterminate & Allred score $\geq 6$ & Qualitative \\
\hline Dehdashti (41) & 11 & $0.69(0.44-0.86)$ & $1(0.83-1)$ & $\mathrm{RBA},>3 \mathrm{fmol} / \mathrm{mg}$ or $\mathrm{IHC}^{*}$ & Qualitative \\
\hline Mintun (42) & 8 & $0.99(0.67-1)$ & $0.05(0-0.67)$ & $\mathrm{RBA},>3 \mathrm{fmol} / \mathrm{mg}$ & Qualitative \\
\hline Mortimer (43) & 16 & $0.76(0.55-0.89)$ & $1(0.83-1)$ & $\mathrm{RBA},>3 \mathrm{fmol} / \mathrm{mg}$ or $\mathrm{IHC}^{*}$ & Qualitative \\
\hline van Kruchten (4) & 22 & $0.95(0.79-0.99)$ & $0.99(0.71-1)$ & $\mathrm{IHC}^{\star}$ or clinical outcome & SUV $_{\max }>1.5$ \\
\hline $\begin{array}{l}{ }^{*} \text { Criteria not stated. } \\
\mathrm{IHC}=\text { immunohisto } \\
\text { Data in parentheses }\end{array}$ & nistr & $\begin{array}{l}A=\text { radioligand } b \\
\text { idence intervals. }\end{array}$ & affinity (50). & & \\
\hline
\end{tabular}




\section{CONCLUSION}

With breast cancer affecting over 3.5 million women in the United States, and with over 330,000 new cases diagnosed each year and over 41,000 deaths per year, the keys to better patient outcomes are earlier detection, better screening, greater awareness, and more effective treatment options. Sometimes breast cancer patients present their medical oncologist with a clinical dilemma on how their particular breast cancer should be treated, especially when standard options fail or are inconclusive. In such cases, nuclear medicine breast imaging has become a diagnostic tool and adjunct to a patient's workup. ${ }^{18} \mathrm{~F}$-fluoroestradiol PET may be a viable option to provide information on the ER status of all tumors in the body-both the primary breast tumor and any metastatic lesions-in a single noninvasive scan. Imaging with ${ }^{18} \mathrm{~F}$-fluoroestradiol PET is like performing a whole-body biopsy to localize all the ER+ lesions. A patient's ER status can change once the cancer has metastasized to other organs; in that event, a treatment option that works for the primary tumor may not work for the metastatic lesions, and vice versa. Knowing the ER status of all tumors is vital to successfully selecting the right treatment for both the primary and any metastases. Especially when standard treatment options fail, ${ }^{18} \mathrm{~F}$-fluoroestradiol PET may be useful in helping medical oncologists learn the ER status of all tumors and determine the best treatment, leading to a better response and outcome.

\section{DISCLOSURE}

Barbara Grabher received an unrestricted grant from Zionexa for the research and creation of this article. No other potential conflict of interest relevant to this article was reported.

\section{ACKNOWLEDGMENT}

I thank Michele Ramsey for helping me with this article.

\section{REFERENCES}

1. U.S. breast cancer statistics. Breastcancer.org website. https://www.breastcancer.org/symptoms/understand_bc/statistics. Revised January 27, 2020. Accessed May 18, 2020.

2. DeSantis CE, Ma J, Goding Sauer A, et al. Breast cancer statistics, 2017, racial disparity in mortality by state. CA Cancer J Clin. 2017;67:439-448.

3. Zionexa announces FDA acceptance for review of new drug application for fluoroestradiol. Zionexa website. https://www.zionexa.com/2019/05/21/zionexaannounces-fda-acceptance-of-new-drug-application-nda-for-fes-fluoroestradiol-f18a-biomarker-for-targeted-imaging-in-metastatic-breast-cancer-mbc/. Published May 21, 2019. Accessed May 18, 2020.

4. van Kruchten M, Glaudemans A, de Vries E, et al. PET imaging of estrogen receptors as a diagnostic tool for breast cancer patients presenting with a clinical dilemma. J Nucl Med. 2012;53:182-190.

5. Breast cancer facts \& figures 2017-2018. American Cancer Society website. https://www.cancer.org/content/dam/cancer-org/research/cancer-facts-and-statistics/ breast-cancer-facts-and-figures/breast-cancer-facts-and-figures-2017-2018.pdf. Published 2017. Accessed May 18, 2020.

6. Metastatic breast cancer. Breastcancer.org website. https://www.breastcancer. org/symptoms/types/recur_metast. Revised January 22, 2020. Accessed May 18, 2020 .
7. About breast cancer: breast cancer basics. American Cancer Society website. https://www.cancer.org/content/dam/CRC/PDF/Public/8577.00.pdf. Revised September 18, 2019. Accessed May 18, 2020.

8. Certain breast changes. Breastcancer.org website. https://www.breastcancer.org/ risk/factors/breast_changes. Accessed May 18, 2020.

9. Types of breast cancer. Breastcancer.org website. https://www.breastcancer.org/ symptoms/types. Revised October 16, 2018. Accessed May 18, 2020.

10. Types of invasive breast cancer.Susan G. Komen website. https://ww5.komen. org/AboutBreastCancer/DiagnosingBreastCancer/UnderstandingaDiagnosis/ TumorTypesSizesGrades.html. Revised September 13, 2019. Accessed May 18, 2020.

11. Tumor grade. National Cancer Institute website. https://www.cancer.gov/aboutcancer/diagnosis-staging/prognosis/tumor-grade-fact-sheet. Reviewed May 3, 2018. Accessed May 18, 2020.

12. NCI Dictionary of Cancer Terms. https://www.cancer.gov/publications/dictionaries/ cancer-terms/def/ajcc-staging-system. Accessed May 18, 2020.

13. Sree SV, Yin-Kwee Ng E, Acharya RU, Faust O. Breast imaging: a survey. World J Clin Oncol. 2011;2:171-178.

14. Joe BN, Sickles EA. The evolution of breast imaging: past to present-figure 4 . Radiology website. https://pubs.rsna.org/doi/full/10.1148/radiol.14141233\#fig4. Published October 23, 2014. Accessed May 18, 2020.

15. Covington MF, Pizzit V, Pockaj B, et al. The future of contrast-enhanced mammography. AJR. 2018;210:292-300.

16. Neovascularization. The Free Dictionary by Farlex website. https://medical-dictionary. thefreedictionary.com/neovascularization. Published 2012. Accessed May 18, 2020.

17. Sensitivity. The Free Dictionary by Farlex website. https://medical-dictionary. thefreedictionary.com/sensitivity. Published 2012. Accessed May 18, 2020.

18. Specificity. The Free Dictionary by Farlex website. https://medical-dictionary. thefreedictionary.com/specificity. Published 2012. Accessed May 18, 2020.

19. Newton E. Breast cancer screening. Medscape website. https://emedicine.medscape.com/article/1945498-overview\#showall. Revised April 10. 2019. Accessed May 18, 2020.

20. Brem RF, Lenihan MJ, Lieberman J, et al. AJR. 2015;204:234-240. 10.2214/ AJR.13.1207.

21. Ultrasound. Breastcancer.org website. https://www.breastcancer.org/symptoms/ testing/types/ultrasound. Revised October 23, 2015. Accessed May 18, 2020.

22. Warner E, Hill K, Causer P, et al. Prospective study of breast cancer incidence in women with a BRCA1 or BRCA2 mutation under surveillance with and without magnetic resonance imaging. J Clin Oncol. 2011;29:1664-1669.

23. Miraluma test. WCG CenterWatch website. https://www.centerwatch.com/druginformation/fda-approved-drugs/drug/271/miraluma-test. Approved May 1, 1997. Accessed May 18, 2020.

24. van Kruchten M, de Vries E, Brown M, et al. PET imaging of oestrogen receptors in patients with breast cancer. Lancet Oncol. 2013;14:e465-e475.

25. Estrotep: radiopharmaceutical approved in France. Zionexa website. https:// www.zionexa.com/estrotep/. Accessed May 19, 2020.

26. Liao GJ, Clark AS, Schubert EK, Mankoff DAF. ${ }^{18} \mathrm{~F}$-fluoroestradiol PET: current status and potential future clinical applications. J Nucl Med. 2016;57:1269-1275.

27. Lindström LS, Karlsson E, Wilking UM, et al. Clinically used breast cancer markers such as estrogen receptor, progesterone receptor, and human epidermal growth factor receptor 2 are unstable throughout tumor progression. J Clin Oncol. 2012;30:2601-2608

28. Yang Z, Sun Y, Zhang Y, et al. Can fluorine-18 fluoroestradiol positron emission tomography-computed tomography demonstrate the heterogeneity of breast cancer in vivo? Clin Breast Cancer. 2013;13:359-363.

29. Gemignani ML, Patil S, Seshan VE, et al. Feasibility and predictability of perioperative PET and estrogen receptor ligand in patients with invasive breast cancer. J Nucl Med. 2013;54:1697-1702.

30. Chae SY, Kim SB, Ahn SH, et al. A randomized feasibility study of ${ }^{18} \mathrm{~F}$ fluoroestradiol PET to predict pathologic response to neoadjuvant therapy in estrogen receptor-rich postmenopausal breast cancer. J Nucl Med. 2017;58:563-568.

31. Peterson LM, Kurland BF, Schubert EK, et al. A phase 2 study of $16 \alpha-\left[{ }^{18} \mathrm{~F}\right]-$ fluoro-17 $\beta$-estradiol positron emission tomography (FES-PET) as a marker of hormone sensitivity in metastatic breast cancer (MBC). Mol Imaging Biol. 2014; $16: 431-440$

32. Mankoff DA, Peterson LM, Tewson TJ, et al. $\left[{ }^{18} \mathrm{~F}\right]$ fluoroestradiol radiation dosimetry in human PET studies. J Nucl Med. 2001;42:679-684.

33. Linden HM, Kurland BF, Peterson LM, et al. Fluoroestradiol positron emission tomography reveals differences in pharmacodynamics of aromatase inhibitors, tamoxifen, and fulvestrant in patients with metastatic breast cancer. Clin Cancer Res. 2011;17:4799-4805.

34. NCCN guidelines insights: breast cancer, version 3.2018. JNCCN website. https://jnccn.org/view/journals/jnccn/17/2/article-p118.xml?utm_source=TrendMD\& utm_medium =cpc\&utm_campaign=JNCCN_TrendMD_0. Published February 2019. Accessed May 19, 2020 
35. Yang Z, Sun Y, Zhang Y. Can fluorine-18 fluoroestradiol positron emission tomography-computed tomography demonstrate the heterogeneity of breast cancer in vivo? Clin Breast Cancer. 2013;13:359-363.

36. How to read hormone receptor test results. BreastCancer.org website. https:// www.breastcancer.org/symptoms/diagnosis/hormone_status/read_results. Revised January 26, 2017. Accessed May 19, 2020.

37. Venema CM, Mammatas LH, Schroder CP, et al. Androgen and estrogen receptor imaging in metastatic breast cancer patients as a surrogate for tissue biopsies. J Nucl Med. 2017;58:1906-1912.

38. Peterson LM, Mankoff DA, Lawton T, et al. Quantitative imaging of estrogen receptor expression in breast cancer with PET and ${ }^{18} \mathrm{~F}$-fluoroestradiol. $\mathrm{J} \mathrm{Nucl}$ Med. 2008;49:367-374.

39. Gupta M, Datta A, Choudhury PS, et al. Can ${ }^{18} \mathrm{~F}$-fluoroestradiol positron emission tomography become a new imaging standard in the estrogen receptor-positive breast cancer patient: a prospective comparative study with ${ }^{18} \mathrm{~F}$-fluorodeoxyglucose positron emission tomography? World J Nucl Med. 2017;16:133-139.

40. Chae SY, Ahn SH, Kim SB, et al. Diagnostic accuracy and safety of $16 \alpha-\left[{ }^{18} \mathrm{~F}\right]$ fluoro-17 $\beta$-oestradiol PET-CT for the assessment of oestrogen receptor status in recurrent or metastatic lesions in patients with breast cancer: a prospective cohort study. Lancet Oncol. 2019;20:546-555.

41. Dehdashti F, Mortimer JE, Siegel BA, et al. Positron tomographic assessment of estrogen receptors in breast cancer: comparison with FDG-PET and in vitro receptor assays. J Nucl Med. 1995;36:1766-1774.
42. Mintun MA, Welch MJ, Siegel BA, et al. Breast cancer: PET imaging of estrogen receptors. Radiology. 1988;169:45-48.

43. Mortimer JE, Dehdashti F, Siegel BA, et al. Positron emission tomography with $2-\left[{ }^{18} \mathrm{~F}\right]$ fluoro-2-deoxy-D-glucose and $16 \alpha-\left[{ }^{18} \mathrm{~F}\right]$ fluoro-17 $\beta$-estradiol in breast cancer: correlation with estrogen receptor status and response to systemic therapy. Clin Cancer Res. 1996;2:933-939.

44. Evangelista L, Guarneri V, Conte PF. ${ }^{18} \mathrm{~F}-$ fluoroestradiol positron emission tomography in breast cancer patients: systematic review of the literature \& metaanalysis. Curr Radiopharm. 2016;9:244-257.

45. Lee VW. A complementary role for thallium-201 scintigraphy with mammography in the diagnosis of breast cancer. $J$ Nucl Med. 1993;34:2095-2100.

46. Prekeges J. Breast imaging devices for nuclear medicine. J Nucl Med Technol. 2012;40:71-78.

47. Fowler AM. A molecular approach to breast imaging. J Nucl Med. 2014;55:177-180.

48. Breast cancer molecular types. Cancer Treatment Centers of America website. https://www.cancercenter.com/cancer-types/breast-cancer/types/breast-cancermolecular-types. Accessed May 18, 2020.

49. Breast cancer grades. American Cancer Society website. https://www.cancer.org/ cancer/breast-cancer/understanding-a-breast-cancer-diagnosis/breast-cancer-grades. html. Revised September 20, 2019. Accessed May 18, 2020.

50. Salem K, Kumar M, Kloepping K. Determination of binding affinity of molecular imaging agents for steroid hormone receptors in breast cancer. Am J Nucl Med Mol Imaging. 2018;8:119-126. 